\title{
Diversity in education: Kenyan sign language as a medium of instruction in schools for the deaf in Kenya
}

Jefwa G Mweri

Correspondence: jmweri2000@yahoo.com

University of Nairobi, Nairobi, Kenya

\begin{abstract}
In Kenya, the only official document that deals with the use of mother tongue (MT) in Schools is the 1967 Gachathi report. The report has clear-cut guidance and policy regarding MT use by the hearing children. However, for deaf children, no such policy exists; therefore, the use of the deaf child's MT (Kenyan Sign Language (KSL)) in schools for the deaf has largely been ignored and there is a continued insistence on the use of the "oral" method of communication that puts emphasis on teaching deaf children how to speak. This continued denial of the use of KSL in schools for the deaf is tantamount to destruction of language and culture of a people and a violation of the deaf children's rights that fundamentally undermines their ability to acquire appropriate education. This is in direct contravention of article 26 of the universal declaration on Human Rights. Similarly, by denying the deaf in Kenya - a language minority the use of KSL - their MT, we are actually squandering a linguistic resource that can be used to impart the knowledge and skills necessary for their survival. This article therefore examines the importance of MT (KSL) in the education of the deaf in learning 2nd and 3rd languages and the way forward.
\end{abstract}

\section{Introduction}

The education of the deaf must be on a realistic view of the linguistic possibilities of the deaf world.... It must be an education that is aimed at giving the deaf knowledge and skills which will make them equal partners to their hearing brothers and sisters in a competitive business of life (Okombo 1992, p. 21).

Cultural diversity is a fact of life. This cultural diversity entails diversity in language use. Language is a system of symbols that people use for purposes of encoding and decoding information. The decoding and encoding of information can be done through an audio based symbol system i.e. spoken language or it can be done using a visual based symbol system that gives rise to written and sign language of the deaf. The audio based symbolic system is the system used by the majority of the estimated world population which, according to United Nations Population Fund (UNFPA 2011) in a state of the world population report entitled: "People and possibilities in a world of 7 billion people", launched on 26th October, seven billion people were expected to inhabit the

(c) 2014 Mweri; licensee Springer. This is an Open Access article distributed under the terms of the Creative Commons Attribution License (http://creativecommons.org/licenses/by/4.0), which permits unrestricted use, distribution, and reproduction in any medium, provided the original work is properly credited. 
earth by 31st October 2011. According to The Galluadet University website, there are estimated 40 million deaf people in the world and who by virtue of their deafness are also a language minority. Although there are a significant number of audio based languages that are minority languages, all sign languages are minority languages in the countries they are used in.

In this article, the term minority languages is defined as those languages that are used by a minority of a certain population of a country. The deaf in any country are a language minority since their mode of communication is used by a very small population in any country. For example, out of an estimated population of 38.7 million (2009 census) people in Kenya, about 600,000 Kenyans are deaf (This is a conservative figure). This is according to the Kenya National survey for persons with disability done in 2008. This article, therefore, focuses on the deaf as a linguistic minority as compared to those that use spoken language regardless of whether such languages are also minority languages on their own right. The numerical majority in the Kenyan population is formed by the hearing population thus leaving the deaf as a clear minority in terms of language and culture. Deaf people are people who for one reason or another have lost their auditory faculty and thus cannot use the audio based symbolic system used by the majority of people. There are varying degrees of deafness but we will consider any person who has lost their hearing as a deaf person.

Because the deaf are a language minority, there is need to protect and preserve their cultural and linguistic identity. In the world today, where an estimated half of the 6000 or so languages in use are on the verge of extinction (Hornberger, 2008), the preservation of both cultural and linguistic diversity is very important. Most of the documented languages that are considered on the verge of extinction are spoken languages. However, not much data is available on signed languages and their status. Being minority languages, therefore, there is every possibility that most of them go unreported and could be part of those that are on the verge of extinction. Similarly, most efforts to promote sign Language has been concentrated on national sign languages at the expense of "village sign Language" that are used in small communities that are also geographically isolated making them vulnerable to extinction. The fact of the matter is that Sign Language has suffered by virtue of being a minority language used by a group who are marginalized due to their disabilities. All people with disabilities suffer some form of marginalization. However, the deaf suffer double marginalization since their disability results into linguistic disadvantage which has been a conduit for exploiting the deaf over the years leading to what (Tonkins 1983, p. 190) calls "oppression, isolation or discrimination against an individual, a community or state". In the case of the deaf, a whole community is condemned to this discrimination.

Kenya is a multilingual society with most Kenyans speaking at least 3 languages: Mother tongue (MT), English and Kiswahili. This generalization is always passed as the true linguistic situation in Kenya. However, on closer examination, we note that it excludes the use of Kenyan Sign Language (KSL). Secondly, most of the deaf are monolingual in the sense that they can only use KSL in most communicative situations. Some may even have no knowledge of KSL let alone of any spoken language. Deaf people who have no knowledge of KSL simply use survival signs and almost meaningless or linguistically unstructured sounds. Often the hearing and even the other deaf people who use KSL have to guess what their intended message is. 
It is important to note at this point that KSL like any other SL is a fully blown language in its right, complete with its own rules of grammar. More importantly, no sign language is based on any spoken language. While spoken language makes use of sounds and letters for communication, SL uses gestures (manual) and Non manual signs. Each country has its own sign language. These sign languages are as different as English is to Kiswahili that is why SL is normally given the name of the country it belongs to. Thus Kenyan Sign Language (KSL), British Sign Language (BSL) etc. A deaf Kenyan therefore cannot communicate with a deaf person from a different country who uses a different sign Language without the use of an interpreter. Using a language that is visual based make the deaf have a unique communication need that by and large denies them access to vital information.

Deaf Kenyans, like their hearing counterparts, need to be able to have access to the larger society. This access definitely is linked to language which opens the doors to the world. They need to be in a position to use their language in an atmosphere that guarantees them access to information and services like anybody else as well as guaranteeing them all the freedoms enshrined in the constitution. They do not require being in an atmosphere where they suffer for being a language minority in a system which still insists that they communicate using speech. The education of the deaf in Kenya is a good example of how the right to education of whole community has been violated thus contravening the UN convention on human rights. This article discusses the situation of the deaf in Kenya, focusing on education, since education has a formative effect on the mind, character and physical ability of an individual.

\section{The infrastructural anomalies in the deaf children's learning environment}

The importance of education in people's lives cannot be gainsaid. This importance is reflected in the kind of infrastructural development that governments engage in as far as education is concerned. In Kenya, for example, the national education budget takes about $37 \%$ of the total national budget. However, a small percentage of this is channeled to special Education. For instance, while the Kenyan government is priding itself in free primary and secondary education, free education has not been implemented in special schools, thus, having a negative effect in as far as special education is concerned. The educational environment, within which the deaf pupils find themselves specifically, is far from being conducive and thus hinders the capabilities of a deaf child from reaching their fullest education potential.

Firstly, the physical environment the deaf children find themselves in the schools is far from conducive in as far as infrastructure is concerned and this impacts negatively on their education. This state of affairs can be exemplified by the words of the Permanent Secretary (PS) in the Ministry of Gender, Children and Social Development in Kenya. While addressing participants at the commencement of the deaf awareness week 2011, he stated: "The deaf were the most likely to be less educated among all persons with disability" (The East African Standard, September 20th 2011, p. 7). In effect, the PS was confirming the truth as stated above. In essence what this means is that the deaf school system in Kenya effectively produces educationally and socially "handicapped" young adults and in so doing helps to perpetuate the belief that as disabled people the Deaf are inadequate, in this way legitimizing their discrimination. 
This has been made worse by the inclusive policy adopted by the ministry of education, which has seen the mushrooming of many units of the deaf across the country in regular schools. The physical environment in the schools for the deaf and the units for the deaf therefore is pathetic to say the least.

Most units for the deaf are situated in regular schools. This means that a school that has predominantly hearing students is required to start a small unit for the deaf within its compound. While the hearing pupils go through school systematically from class 18 , and don't experience any mixing of pupils of different classes in the same room, this is the order of the day in most units for the deaf. In other words, it is not uncommon to find pupils who are in different stages of learning all mixed up in one classroom. Some questions that one may ask are: How possible is it for one teacher to teach pupils of different ages and levels in terms of class in the same room at the same time? How is it possible to teach such children who obviously have different linguistic capabilities together?

The schools for the deaf maybe better in terms of infrastructure as compared to the units since they were established as institutions for the deaf. But as pointed out earlier, very little or no funds are remitted to these schools. As if that is not enough, most parents with deaf children are poor and cannot therefore afford to pay the fees charged in these schools. As a result, we have a huge drop-out rate of deaf children at all levels of education. With this kind of learning environment, therefore, it is little wonder that since independence, no deaf person educated in Kenya has reached the high echelons of education or professionalism in almost all the fields. Would this kind of environment be allowed to happen in regular schools with hearing pupils?

Secondly, the quality of teachers posted to these institutions for the deaf is below par. Most are professional teachers, but they lack the linguistic knowhow to use KSL to impart knowledge to the deaf. According to Okombo (1992, p. 21):

For thirty years, our teachers have tried to speak to deaf children but they have failed. And because of this failure, our teachers have come to the conclusion that the Deaf are not meant for college and University education. The teachers feel successful if a deaf child is able to mumble some few words and can do some elementary job as a craftsman, say in a carpentry shop. This is what we call Deaf Education in Kenya.

Teachers in educational institutions are supposed to impart knowledge to students through the various subjects they teach. However, in the institutions for the deaf, the teachers are handicapped linguistically and therefore little or no learning takes place. This is because while the deaf use a visual mode of communication, the teachers, most of whom are hearing, use the oral mode of communication. If education is responsible for the transmission of a people's culture or accumulated knowledge from one generation to the next, this function of education for the deaf is non existent. Something needs to be done and really fast to salvage this sad situation in Kenyan schools and units for the deaf.

\section{KSL, the Mother Tongue for the Deaf}

Mother tongue or L1 can be viewed as the language that one learns at home mainly from parents. In some quarters, it is viewed as the language of one's ethnicity, 
sometimes disregarding one's proficiency in the same. In the Kenyan multilingual scenario, the significance of MT cannot be gainsaid as was acknowledged by the Gachathi commission report of 1976, which recommended that the language used in a school's catchment area should be the medium of instruction in lower primary School (Std. 1-3) and that it must be taught as a school subject. From class 4 onwards English takes over as the medium of instructions.

This report, I believe, was informed by the need to circumvent what Cummins (2003) calls the "Assimilationist Policies" in education which discourage students from using their mother tongue. "Assimilationist policies" are based on the belief that usage of MT is not only detrimental to national integration, but that it is also an inadequate tool for teaching educational concepts and knowledge. In Kenya, for example, students are at times punished physically for using their MT in schools in efforts to promote use of the official language.

For the deaf child, the language problem is even bigger. 90\% of these deaf children are born to hearing parents who often have no knowledge of SL. Parents who do not understand the deaf child's mother tongue often insist on the child learning their (parents') MT, which is an audio as opposed to visual language. To compound this problem, a majority of deaf children can neither learn KSL at home nor can they learn the "language of outside" which the hearing child learns simultaneously with their MT. This is because, for the deaf child, that "language of outside" - Kiswahili or English for most hearing children-is audio and hence inaccessible.

Only $10 \%$ of deaf children are lucky enough to be born in an environment that permits them to learn their MT naturally as it should be (Davis 2007, p.5). Either their parents have taken time to learn sign language or they acquired it naturally in their homes where their parents are deaf and therefore use sign language as the language of the home. However, this unique scenario is responsible for the fact that only a few of these, $90 \%$ of deaf children who go to schools of the deaf, end up learning their mother tongue from fellow deaf children if a conducive learning environment exists. In many cases, this does not happen because of other problems within the school system like the insistence on oralism and the "Assimilationist Policies" in education which discourage students from using their mother tongue.

One major problem is that in many schools for the deaf, teachers have often used the assimilationist approach in teaching language to the deaf. This approach means teaching the deaf children how to speak (oralism) in an attempt to make them as "normal" as the others. It is important to note that a born deaf or a profoundly deaf person has no ability to learn a spoken language, especially to speak it as is implied by the oralism approach. Deaf people have the capacity though to learn a spoken language to be able to read (silently) and write it if the approach used for teaching is appropriate. In other words, any appropriate approach to Deaf Education must realistically be visual.

Teaching the deaf how to speak does not make the deaf equal partners to their hearing siblings. If the deaf cannot hear, how can they be expected to speak? The deaf need a visual language. There must be clear-cut language policies that recognize SL as the MT for the deaf. In Kenya, the deaf must be allowed to get their education through the use of KSL as a medium of instructions in their schools. The National Special needs education policy of 10th March 2010 launched by the Ministry of Education, tries to address this issue but the policy is long on intentions but short on specifics. It does 
not, for instance, take into consideration the unique needs of each disabled group. For example, the needs of one who is physically handicapped but who can hear are different from one who is lame but also deaf. A blind person may need a cane and Braille in school for purposes of learning but a deaf- blind person may need much more than this. Lumping all the disabled people in one group, then having one policy to manage them, does not effectively address the needs of each group with their disabilities. A realistic policy should take into cognizance their unique needs. For the deaf who are the subject of this article, for example, KSL as a MT must be taken into consideration. It is, therefore, unrealistic to plan the same kind of special education for children with different disabilities.

It seems that those involved in education planning take special education to mean education of the disabled and do not consider the differences between the disabilities. It is not enough to come up with high sounding vision and mission statements as exemplified in the National Special Needs Education Policy seen below:

Vision: to have "A Society in which all persons regardless of their disability and special needs achieve education to realize their full potential".

Mission: "To create a conducive environment for learners with special needs and disabilities in order for them to have equal and relevant education and training".

These are high sounding ideals but the reality on the ground is totally different. It is unfair to start with lumping together people with disabilities with others who only have special needs but are not disabled. This is a pointer to the lack of understanding on these issues by the policy makers who in most cases are not disabled themselves. The mentality of these policy makers is that "we are helping these people". Disabled people do not need help per se. They need clear policies that they are also involved in identifying and proposing what will give them equal opportunities like their able bodied and hearing brothers and sisters.

The same "helping" mentality is captured in the lack of a clear cut policy on MT use in Deaf Education. The recommendations that the language used in a school's catchment area should be the medium of instruction in lower primary school (Std. 1-3) and that the same subject must be taught as a school subject from class 4 onwards while English takes over as the medium of instruction (GOK 1976), does not seem to cover the deaf. It appears like the policy was formulated with the hearing in mind. For the case of the deaf, they ideally require the use of their MT (Kenya Sign Language (KSL)) as a medium of instruction from kindergarten to college and university. At the same time, KSL could also be taught as an optional language in the curriculum. As it is now, there is no language policy in place to promote the use of KSL in schools for the deaf.

Any language policy for the deaf education should take into consideration teaching academic content in KSL. In regular schools the recommendation is that academic content be taught in two languages i.e. MT (class 1-3) and English thereafter - this being a form of transitional bilingualism used mainly for English only acquisition. For the deaf, the medium of instruction should be KSL, which is also their mother tongue. However, after class 3 when the pupils in regular schools are switching from one spoken language to another as a medium of instruction, the deaf should continue to use KSL as a medium of instruction and use it to learn second, third or more (spoken) languages. This can be referred to as late-exit or developmental bilingual education. 
It occurs in situations where education is done in the child's native language for an extended duration. In this case the deaf in Kenya should use KSL throughout their educational life. At university or college level, deaf students should be provided with interpreters. This approach is important since it would ensure that the deaf develop literacy in their native language first, and then transfer these skills to learning a second, third or fourth spoken language and other academic subjects.

The deaf learners like any other learners would definitely learn faster and much easier since they would be using their MT as a building block for learning. As indicated earlier in this article, the deaf can only learn spoken languages, for example, English and or Kiswahili for purposes of being able to read (silently) and write not to speak them. There is no doubt that the use of MT (KSL) has benefits to the user. UNESCO studies, for example, have shown that learners who go through basic education in their own language perform better than those only educated in English. Those educated in English only in Kenya, for example, may not compete effectively with those educated in English only in for instance in England who use English as their MT. This is because children in our education system are bombarded with foreign languages in schools at the expense of their own MT and they may not develop adequate skills in them comparatively as would the native speakers of those languages. Late-exit or developmental bilingualism is the way to go in Deaf Education since it has immense benefits for the deaf child. It affects the deaf child positively both in terms of language and education. The deaf child will develop literacy in many languages and this will assist him/her in his or her thought process too and also in gaining access to the real world.

\section{Positive effects of KSL as MT on a deaf child's linguistic and educational development}

MTs are important in assisting in the development of strong literacy abilities. As Cummins (2003) notes, children who come to school with a solid foundation in their mother tongue develop stronger literacy abilities in the school language. MT learning and development is part of the process in which the child also learns values, culture and the worldview. Acquisition of language goes hand in hand with the acquisition of a worldview.

In terms of literacy skills, children are better placed to become literate if they learn from the first instance in their first language (MT). This then gives them a chance to move gradually to another language. Deaf education requires a bilingual or multilingual approach. The bilingual approach that Deaf Education is must adopt what Hornby (1977) refer to as additive bilingualism which gives positive values to both the first language (MT) and the second language. This approach, therefore, builds on the first language for purposes of learning a second language (spoken).

Deaf education in Kenya currently uses more of subtractive than the additive approach since a second language, in this case English, is acquired without much regard to the already developed language skills of the first language (MT-KSL). Deaf children are "forced" to learn English without much reference to KSL in most institutions of the deaf. This state of affairs is not desirable at all. There is need to have a policy that clearly is based on MT bilingualism for the deaf, where KSL is used to teach skills such as beginning reading and writing of second language(s) which are mostly spoken languages along with academic content. It is important to note that a deaf person who does not have skills in KSL, for example, will find it difficult to learn a second language 
(mostly spoken). The curriculum used for teaching MT in Kenyan schools as per the Gachathi Report is vague since it is not language specific making it difficult for it to be followed even by those in regular schools. The importance of SL (MT) in the life of the Deaf is captured in the words of (Ndurumo 1988, p. 49) when he asserts: “...sign language is the principle catalyst in the deaf child to various values and opportunities in the hearing world such as education, professional advancement, social integration and psychological adjustment". He also points out the following factors, among many, as the ones that underline the importance of SL in the life of the deaf. That it:

i. Removes invisibility of deafness

ii. Fosters pride and identity among the deaf

iii. Builds language competence

iv. Facilitates learning

v. Expand educational opportunities

vi. Expand professional opportunities

vii. Crystallizes intellectual ability of the deaf

The use of sign language will open up the world of the deaf in many ways - in the field of education where if used as a LOL then it will enable the deaf develop to their fullest potential in terms of education; it will enable deaf people access information which often times is in deaf unfriendly media; it will enable the deaf access services which they cannot access at the moment among many other advantages. The use of SL will enhance their linguistic competence in both Sign language and Spoken language in the sense that deaf people will learn sign language skills just like hearing people learn spoken language skills. For instance, just because one is born a French speaker does not in any way mean that he or she can read and write French. You need to learn how to do it. The same is true for deaf people. Deaf people have the potential for learning any spoken language. However, they only learn a spoken language for purposes of reading and writing and not speaking it. Reading and writing are visual and are not based on sound.

Through the use of SL, therefore, deaf people are able to live a normal life. SL as a MT for the deaf will promote both the development of the MT itself and the child's ability to learn any spoken language. Although Ndurumo (1988) presents a substantial number of advantages of using SL as the MT of the deaf, we wish to go further and explain these advantages in light of their role in learning second and subsequent languages as well as the use of KSL in the academic development of the deaf child.

\section{The role of SL (KSL) in learning a second and third language}

Most teachers for the deaf and educational officials in the field of special education in Kenya have the misconceived idea that using MT as medium of instruction in schools would interfere with the child's academic development in the school's majority language (English). It is not uncommon to hear a teacher remark that deaf children cannot speak or write English correctly, or that they use broken English. Let us take an example of a KSL sentence below:

\section{KSL: TIME PUBERTY GIRL PREGNANT PHYSICAL POSSIBLE CATCH.}

ENG: During puberty, a girl is physically able to become pregnant. 
It is important to note that the above sentence is written in capital letters because each "word" represents a sign and not a word in English or any language for that matter. The sentence above can be transcribed in English as follows: During puberty, a girl is physically able to become pregnant. The KSL and English sentences are structurally different though they express the same idea.

First and foremost, we must understand that we are dealing with two languages that are structurally different. English, a spoken language, and KSL, a signed language. We should also note that each language has its own strategies of expressing ideas etc. and that even within spoken languages there is use of different strategies for communication. Kiswahili, for example, would express the same KSL sentence above as follows: "Msichana anapo balehe anaweza kupata mimba". One wonders why most teachers expect the KSL structure to fit that of English, which is the genesis of the assertion that deaf children make wrong English sentences. KSL, unlike most spoken languages, in its structure uses more content words than functional words. KSL sentences carry the words that make meaning. To illustrate this further, let us take a simple sentence expressed in KSL and in English and Kiswahili.

\section{KSL: MOTHER MINE SLEEP FINISH.}

English: My mother is asleep.

Kiswahili: Mama yangu amelala.

The sentence, MOTHER MINE SLEEP FINISH is a KSL sentence and not an English sentence. The English words used have been capitalized as explained above to show that they represent the concepts they stand for and not words in English. That is why the word MOTHER can also be replaced by mama in Kiswahili since the concept they represent is the same. In KSL, as you can note, there is no use of the auxiliary verb "is" as is the case in English. What teachers must comprehend is that through the use of KSL, they can teach the deaf children "proper English" since they will be able to explain to children that while in KSL we say MOTHER MINE SLEEP FINISH. In English, we say "My mother is sleeping" and in Kiswahili, "Mama yangu analala". The teachers can go further and explain the function of the auxiliary verb in English which is not there in KSL or in the Kiswahili sentence. They could also explain that KSL uses the completive marker FINISH to mark an action that is complete and that in Kiswahili the possessive 'yangu' is optional since it is mainly used for emphasis since one can simply say "Mama analala" to convey the same meaning.

It is clear from the above that each language has its own structure that is sufficient for communication. It is therefore foolhardy to try and create and introduce a sign for "is", for example, in the KSL sentence above so as to make it fit into the English structure so the deaf may use "proper English". This kind of attempt of trying to make SL conform to the structure and rules of English is what gave rise to the artificial signed exact English (SEE) also known as manually coded English (MCE). Though manual like SL, SEE tries to represent exactly how English sentences are made. It, therefore, uses English lexicon and grammar but uses signs instead of English words. Thus SEE tries to force the structure of English onto SL so as to make deaf children communicate in 
"correct" English. SEE has failed wherever it has been introduced since it is based on a false premise that the hearing language is better than a signed one. According to (Yule 2004, p. 175) using SEE, "It's sort of like producing messages with German word order, but containing French nouns, adjectives and verbs. The product is neither French nor German...." The truth of the matter is that every language has its own structure that enables it to function independent of any other and that any attempt to subordinate one language over the other is misplaced.

The introduction of SEE was borne out of an approach that basically concentrates on "language deficits" found among the deaf (Svartholm, 1994, p. 61). Comparisons between the reading and writing ability of deaf children vis-a vis those of hearing children according to Svartholm (1994, p. 61), describe deaf children as "lagging behind" hearing children and being "retarded" and delayed in their language development. However, the comparison is normally fallacious since it compares the hearing child who uses their MT or a spoken language to learn reading and writing while the deaf child is learning a spoken language without proper grounding in their own MT which is often denied them in School.

For children to learn a second language (L2), they must be competent in a first language (L1) or what we have referred to here as (MT). Given that we would not expect a blind person to learn English for instance by seeing the graphic symbols used in its written form, we should not also expect deaf people to learn English or any spoken language by hearing it. This is because SL and spoken language are worlds apart. According to Svartholm (1994, p. 64), the audio language "whether spoken or used in written form, is simply not language when looked upon from the deaf child's point of view. For any child, whether hearing or deaf, language is something used - and acquired, in social settings....".

Chaudron (1988) says that in a learning situation where only L2 is used as a medium of instruction, learners face problems because their task is three fold. The first is that the learner has to make sense of the instructional task which is presented in the second language. Secondly, the learner has to attain linguistic competence that is required for effective learning to take place and finally, the student is faced with the problem of mastering the content itself. These findings were on studies done on spoken language. For the deaf, the task of learning a second language that is distinct from their L1/MT is even more demanding. But this does not mean it cannot be done.

Teachers of the deaf have an important role to play in making sure deaf children are competent in their L1/MT to enable them learn other languages and academic content. Ideally, SL should be used not only as a medium of instruction; it should also be used throughout the school day in instruction of other subjects too. However, as pointed out earlier in the Kenyan scenario, the teachers are the ones that are handicapped since in most cases they are not linguistically equipped to impart knowledge using KSL. They are not competent in the L1 of the deaf - KSL- and thus fail to prepare the deaf child for full integration into the real world. The importance of this L1 to the deaf, just like any other L1, signed or spoken, is captured by (Anderson 1994) who asserts that L1 is used:

i. To express and understand feelings

ii. For socialization

iii. For giving and receiving information

iv. Creatively, for instance, for telling jokes 
Therefore, it is clear that one requires a good command of L1 to enable him or her to conduct "complicated mental operations" (Anderson 1994, p. 64) such as learning a second a language. For the deaf, the second language will be in the reading and writing variants. While deaf people have no capacity to learn a spoken language so as to speak it, hearing people have spoken language and written languages as structural variations of the same language. For deaf people who may not have heard sound, they cannot associate words they read with sounds.

\section{The use of KSL in the academic development of the deaf child}

KSL, the LI or MT for the deaf child in Kenya, like any other MT, is fragile and needs to be taken care of in the early years otherwise it can easily be lost. This is the case in most schools for the deaf in Kenya where for a long time teachers have tended to discourage its use and also tried other means other than the correct ones to try and communicate with the deaf child. KSL or any other sign language for that matter has an important role to play in the academic development of the deaf child.

In countries that have adopted the use of their national signed languages as the medium of instruction in school for the deaf, an unprecedented success has been achieved in the education of the deaf. France for example, is one such country that adopted sign bilingualism. This is the kind of bilingualism where the deaf use two languages in different modalities both of which are spoken. In sign bilingualism, deaf children use sign language as a LOL but they also use it to learn spoken language in its written or read form. In the French scenario, SL is used as a medium of instruction thus learning academic content using it and at the same time use it to learn other languages. This approach is very beneficial to deaf children because they get to learn other subjects as well as other languages using their MT (Ahlgren and Hyltenstam 1994). The second scenario where deaf children are forced to learn two or more spoken languages with little recourse to their MT as is the case in Kenya makes the deaf children appear incompetent in learning other languages and even academic subjects.

Benson (2004) talks of myths and attitudes regularly used to challenge use of mother tongues in education which can also explain the attitudinal difficulties that teachers encounter. Some of the myths she identifies include:

The one nation - one language myth: this myth was perpetuated by the colonial powers to indicate that national unity can only be consolidated using a so called neutral language which more often than not is a foreign one. Benson (2004) argues that this is a myth because there are many cases of monolingual countries which have not enjoyed political stability. Such countries include Somalia, Burundi, Rwanda and others. The one nation - one language myth goes hand in hand with the myth that local languages cannot express modern concepts. For a long time this was the argument against the use of Kiswahili in Kenyan schools until recently when it was realized that Kiswahili can effectively express complex ideas. The same argument today is used against KSL. The fact of the matter, as Benson (2004, p. 8) asserts, is that "all human languages are equally capable to express their speaker's thoughts and can develop new terms and structures as needed".

The other myth Benson (2004) discusses is the either or myth. The perpetuated myth is that for a person to effectively learn L2, then, he/she must discard his/her L1. 
The feeling is that bilingualism causes confusion thus for the child to learn L2, L1 must be discarded. In most countries, there is a movement against bilingualism especially in as far as Deaf Education is concerned. However, to the contrary, the more a child is competent in their L1 or MT, the more they are likely to learn a second language easily because they will build their language and cognition based on the L1.

These and other myths help explain the negativity that KSL has attracted among teachers of the deaf and even policy makers. However, for the deaf child to learn to his/ her full potential, there is need to adopt a realistic view that encompasses all the linguistic possibilities of the deaf world and this entails recognizing the important role that a visual medium plays in the lives of deaf people and recognizing how paramount KSL is in opening up the deaf world and according them equal access and opportunities to deaf Kenyans. KSL, therefore, must feature prominently in the school life of the deaf.

\section{Way forward}

First and foremost, it is important to note that to reject a child's language in the school or anywhere is to reject the child. This is the biggest violation of any person's rights since it fundamentally denies one the access to society. This has been the life of deaf Kenyans over the years. They either have not had access to society or even if they have it, it has always been limited due to their unique communication needs.

As we have mentioned earlier on in this article, an important step in rectifying or addressing this anomaly as far as deaf children are concerned, is the introduction of signed bilingualism - this is the type of bilingualism that recognizes the use of two languages in different modalities; that is, signed and spoken languages (Oracha 2004). Through this, the Deaf Education will open up and enable the deaf to compete effectively with their hearing counterparts. It would require that there is early detection of deafness and therefore early interventions by taking the children into pre-school programs that use KSL. These programmes will help the deaf child in its social, linguistic and intellectual development based on a realistic view of the linguistic possibilities of the deaf world - visual communication. The introduction of signed bilingualism will enable the deaf child establish contact with other deaf children given that most deaf children grow in isolation.

Secondly, the involvement of parents with deaf children in all their programs is essential. Allan (1986) asserts that $90 \%$ of deaf children are born of hearing parents. The implication of this is that many parents with deaf children cannot communicate with their children and that most deaf children do not learn SL naturally. Thus, parents must be made aware that a deaf child is normal but for the use of a language that is different in terms of modality. They must be made aware that it is important for their deaf children to learn SL for ease of communication with the outside world. It is equally important for the parents themselves to learn SL for ease of communication with their own children and for ease of parenting. It would enable them have a normal relationship with their children in terms of interaction and which can only be possible through communication. Parents and schools should also make use of deaf role models to encourage the deaf child and also boost their confidence and self esteem.

A good deaf education program must revolve around the child's needs. In deaf education, the child must be an active participant and not a passive one. This participation 
must mostly be visual so that the environment the deaf child operates in, say in the classroom, is one of more of seeing than of hearing. Participation for the deaf children means it increases the possibility of their being able to develop different skills and also master the world around them. Participation also enables the deaf child develop the value of cooperation as they enjoy and play with other deaf children and in the process it enhances their ability to acquire visual language, in this case KSL.

The teachers' role cannot be overemphasized. Given their central role in the lives of the deaf child, all teachers in schools for the deaf must become fluent in KSL. This may seem to be a difficult feat to achieve. However, through deliberate in-service programs for teachers, where the emphasis will be KSL for specific purposes, it can be achieved. Already teachers in these schools are experts in their teaching subjects. Thus, they only need to learn signs that can facilitate imparting the knowledge they have in a language understood by the deaf; that is, SL and a vocal language in its written and not spoken form. Teachers must also ensure the class arrangement is appropriate since the pupils must be in a position where they can see the teacher and also see each other. The classroom must also be visual, as earlier indicated, thus there must be plenty of pictures, diagrams. The classroom must be well lit since the language used is visual; the teacher must draw the attention of who is communicating at all times.

The government cannot be left out in Deaf Education since it has an obligation through its policy makers to establish realistic policies in as far as Deaf Education is concerned. It must be prepared to fund Deaf Education fully on the understanding that its previous policies have impoverished the deaf population and thus majority of parents cannot afford to pay for their deaf children. Thus, a form of affirmative action for the deaf in terms of education would be in order. The policies developed must not lump together all disabilities but must consider the specifics of each disability. They should realize that children with different disabilities have different educational needs. The current policy on integration may work well for children with certain disabilities but not all. Physically disabled children can be integrated much easier in a regular hearing school than a deaf child. As long as the infrastructure is right for mobility's sake, the physically disabled child who can hear can effectively take instructions through speech. A deaf child may not have a problem with mobility but integrating him/her in a hearing school is disadvantageous. It may affect his/her self-esteem given the unfavourable environment. It may mean all teachers that come into contact with this deaf child must learn SL, a feat that is probably unattainable.

\section{Conclusion}

While thousands of deaf adults have been condemned to a life of misery over the years due to misplaced educational policies in Kenya, this need not also happen to the present generation of deaf children. We need to address their plight sooner than later to enable them become productive members of society. Deaf people in countries that have recognized their national sign languages have been able to become professionals in different fields and some have become professors. This is also possible with deaf Kenyans. The constitution in place in Kenya today, provides a window of hope and opportunity since for the first time it recognizes the role of the state in promoting and developing the use of indigenous languages among them KSL (Article 2, Section 7 3b). 
It also recognizes KSL as one of the languages of parliament (Cap. 8. Section 129. 1). If these provisions are followed to the later, they will accord the deaf citizen of a new Kenya a new beginning by enabling them to compete effectively with their hearing counterparts and it will also open up the deaf world since the recognition and use of KSL as the medium of instruction in Schools for the deaf is inevitable - it is just a matter of time.

\section{Competing interest}

The author declares that he has no competing interests.

\section{Acknowledgements}

Research on this article would not have been possible without the unwavering support from the Kenyan deaf community in general who have had me in their midst since 1991 and the deaf and hearing project staff at the Kenya |Sign Language Research Project University of Nairobi who ensured i perfected my Kenyan Sign Language and broadened my research horizons over the years.

Thank you all.

Received: 5 March 2014 Accepted: 15 July 2014

Published: 12 August 2014

\section{References}

Ahlgren, I, and K Hyltenstam (eds.). 1994. Bilingualism in deaf education. International Studies on Sign Language and Communication of the Deaf Vol. 27. Hamburg: Signum.

Allan, K. 1986. Linguistic meaning Vol. 2. New York: Routledge.

Anderson, R. 1994. Second language literacy in deaf students. In Ahlgren and Hyltenstam (Eds.). Bilingualism in Deaf Education (pp. 91-101). Hamburg: Signum.

Benson, C. 2004. The importance of mother tongue- based schooling for educational quality, Paper commissioned for All Global Monitoring Report 2005. The Quality Imperative.

Chaudron, C. 1988. Second language classroom: Research on teaching and learning. Cambridge: Cambridge University Press.

Cummins, J. 2003. Bilingual children's mother tongue: Why it is important for education. Toronto: University of Toronto Press.

Davis, LJ. 2007. Deafness and the Riddle of Identity. The Chronicle Review 53(19): B6-5. Washington D.C.

GOK. 1976. National committee on educational objectives and policies. The Gachathi Report.

Hornberger, NH (ed.). 2008. Can schools save indigenous languages? Policy and practice on four continents. New York: Palgrave Macmillan.

Hornby, PA. 1977. Bilingualism, psychological, social, and education implications. New York: Academic Press.

Ndurumo, M. 1988. The significance of sign language among the deaf, A paper presented at the first East African Sign Language conference. Arusha, Tanzania.

Okombo, O. 1992. Bilingualism in the schools for the deaf. In proceedings of East African Sign Language seminar. Nairobi, Kenya.

Oracha, PO. 2004. Advantages of sign language in Deaf Education. In Journal for Disability and International Development, 24-29. Behinderung und Dritte Welt No. 1/2004.

Svartholm, K. 1994. Second language learning in the deaf. In Bilingualism in Deaf Education, ed. I Ahlgren and K Hyltenstam, 61-70. Hamburg: Signum.

The East African Standard, September 20th. 2011. "Deaf awareness' week". Nairobi. Kenya.

Tonkins, H. 1983. Language and international communication. In The right to communicate: A new human right, ed. D Fischer and LS Harns, 196-210. Dublin: Book Press.

UNFPA. 2011. State of the world population report: People and possibilities in a world of 7 billion people.

Yule, G. 2004. The study of language. United Kingdom: CUP.

doi:10.1186/s13616-014-0014-1

Cite this article as: Mweri: Diversity in education: Kenyan sign language as a medium of instruction in schools for the deaf in Kenya. Multilingual Education 2014 4:14. 